\title{
A novel technique for endoscopic removal of foreign bodies using a balloon and transparent cap
}

The presence of foreign bodies in the esophagus is a common clinical emergency and induces discomfort in patients, including chest pain or dysphagia, but may also result in more severe complications, such as hemorrhage and esophageal perforation [1]. We report a novel method of removing large foreign bodies using a balloon with the assistance of a transparent cap.

A 68-year-old woman was referred to our department complaining of chest pain following ingestion of a round-shaped stone 3 days earlier. On computed tomography scan, a high-density object approximately $3 \mathrm{~cm}$ in length was observed in the mid-esophagus ( $\triangleright$ Fig. 1 ). Multiple attempts to remove the stone failed ( $>$ Fig. 2). Therefore, we developed a new retrieval method using a transparent cap and dilation balloon (Vedkang, Changzhou, China) ( $\triangleright$ Fig.3). The deflated balloon, together with a transparent cap, was attached to the distal end of the endoscope, and then inserted into the esophagus. Subsequently, once the end of the endoscope reached the foreign body, $20 \mathrm{~mL}$ of air was injected into the balloon through a thin catheter, expanding its outer diameter from 1.3 to $3.5 \mathrm{~cm}$. As the balloon was inflated, the narrow esophageal lumen gradually dilated, allowing the stone to be pushed into the stomach. The stone was eventually extracted using a disposable polypectomy snare ( $\mathbf{F i g . 4 ) . ~ M i l d ~ h e m a t o m a ~ a n d ~ m u - ~}$ cosal injury were observed at the original site of the stone, without perforation, infection, or other complications ( $\mathbf{F i g . 5}$, $\checkmark$ Video 1 ).

The balloon was originally designed for endoscopic injection sclerotherapy to treat esophageal variceal hemorrhage [2]. We demonstrated that this approach was also safe, simple, and highly effective for extraction of foreign bodies in the esophagus, particularly for large or

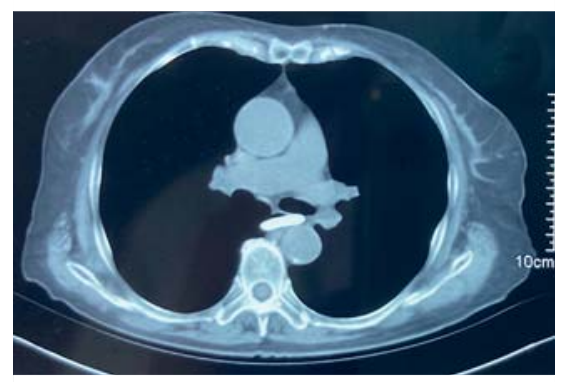

- Fig. 1 A high-density object, approximately $3 \mathrm{~cm}$ in length on the computed tomography scan, was observed in the mid-esophagus.

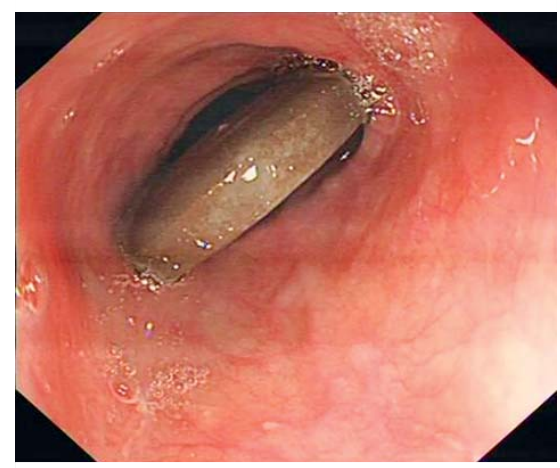

- Fig. 2 Although various attempts were made using different methods, the stone remained in the esophagus.

sharp objects. Thus, we highly recommend balloon-assisted endoscopy as a feasible technique worthy of clinical promotion.

Endoscopy_UCTN_Code_TTT_1AO_2AL

Funding

The Research Fund Project of Anhui Provincial Institute of Translational Medicine 2017zhyx18

The Anhui Science and Technology Department: 2018 Key Research and Development Plan Projects 1804h08020260

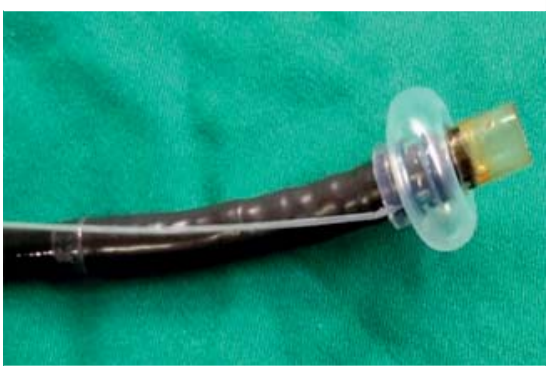

Fig. 3 A self-designed balloon, together with a transparent cap, was attached to the distal end of the endoscope and inflated with $20 \mathrm{~mL}$ of air, expanding its outer diameter from $1.3 \mathrm{~cm}$ to $3.5 \mathrm{~cm}$.

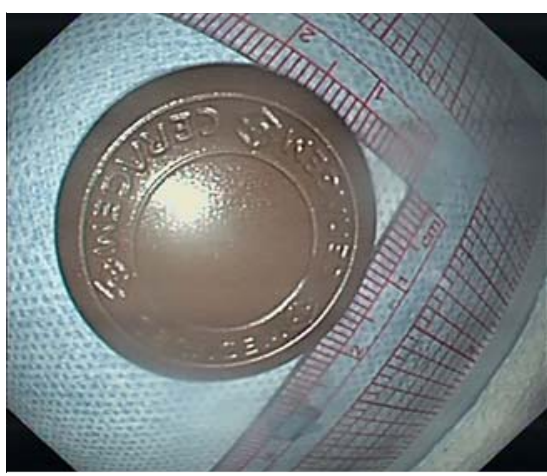

- Fig. 4 The round-shaped stone was extracted using a disposable polypectomy snare after being pushed into the stomach.

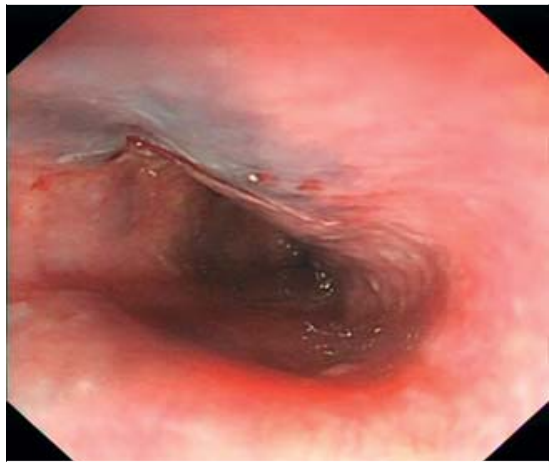

Fig. 5 Mild hematoma and mucosal injury were observed at the original site of the stone, but without perforation, infection, or other complications. 


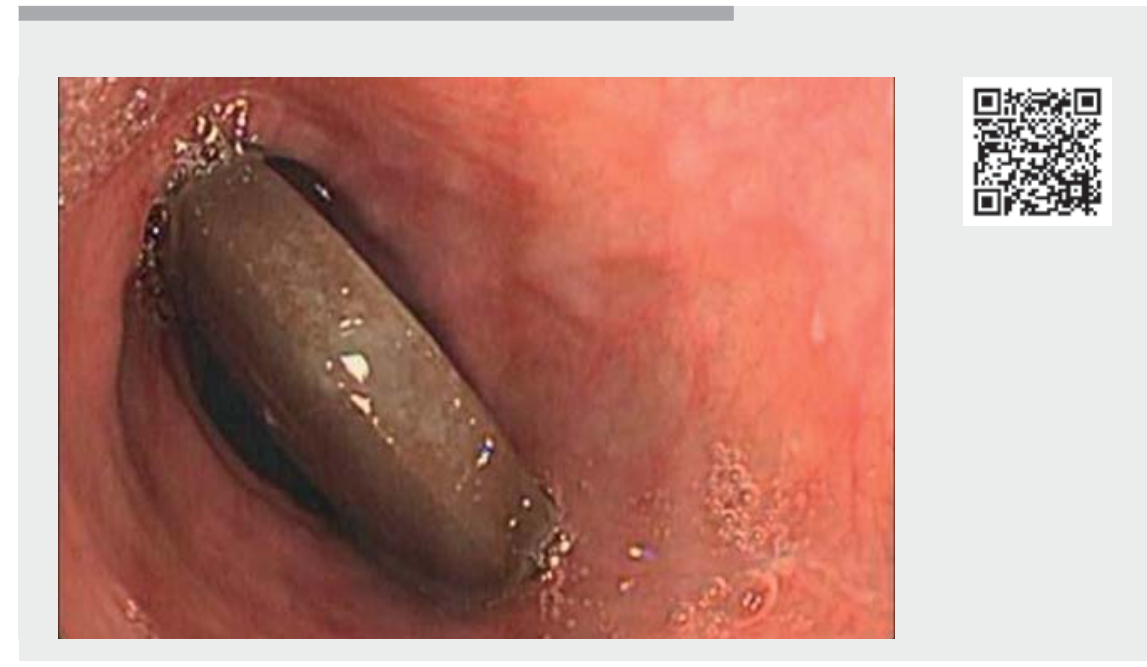

Video 1 A novel technique for endoscopic removal of foreign bodies using a balloon and transparent cap.

\section{Competing interests}

The authors declare that they have no conflict of interest.

\section{The authors}

Wenyue Wu' ${ }^{1}$, Yi Han², Derun Kong ${ }^{1,2}$

1 First Affiliated Hospital of Anhui Medical University, Hefei, China

2 Fuyang Hospital Affiliated to Anhui Medical University, Fuyang, China

\section{Bibliography}

Endoscopy 2022; 54: E149-E150

DOI 10.1055/a-1407-9895

ISSN 0013-726X

published online 20.4.2021

(c) 2021. Thieme. All rights reserved.

Georg Thieme Verlag KG, Rüdigerstraße 14,

70469 Stuttgart, Germany

\section{ENDOSCOPY E-VIDEOS \\ https://eref.thieme.de/e-videos}

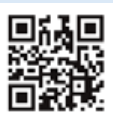

Endoscopy E-Videos is an open access online section, reporting on interesting cases and new techniques in gastroenterological endoscopy. All papers include a high quality video and all contributions are freely accessible online. Processing charges apply (currently EUR 375), discounts and wavers acc. to HINARI are available.

This section has its own submission website at https://mc.manuscriptcentral.com/e-videos

\section{Derun Kong, MD}

Gastroenterology Department, First Affiliated Hospital of Anhui Medical University, Jixi Road 218, Shushan District, 237000 Hefei, Anhui, China kongderun@ahmu.edu.cn

\section{References}

[1] Triadafilopoulos G, Roorda A, Akiyama J. Update on foreign bodies in the esophagus: diagnosis and management. Curr Gastroenterol Rep 2013; 15: 317

[2] Mei X, Wang X, Wu W et al. Balloon-assisted endoscopic sclerotherapy: a novel technology. Endoscopy 2020. doi:10.1055/a-12907001 